\title{
Encontro de Mulheres no CRAS: Uma Experiência na Construção Grupal
}

Meeting of Women at CRAS: An Experience in Group Construction

Encuentro de mujeres en el CRAS: una experiência en la construccion de grupos

Deise Lucia Antunes Lopes

Kátia Maheirie

Ana Maria Justo

Universidade Federal de Santa Catarina (UFSC), Florianópolis, SC, Brasil

\begin{abstract}
Resumo
Este estudo é resultado de uma pesquisa-intervenção realizada com um grupo de mulheres que participam de uma atividade regular em um CRAS da região metropolitana de Florianópolis SC. O objetivo do artigo é apresentar e discutir o diário de campo produzido entre junho de 2017 a dezembro de 2018. As informações foram sistematizadas com o auxílio do software IRAMUTEQ que permitiu a identificação das categorias de análise do estudo, por meio da Classificação Hierárquica Descendente (CHD), distinguindo quatro classes que foram objeto de discussão e analisadas a partir da dialética de grupos de J. P. Sartre. Os resultados apontaram que a experiência grupal permitiu o estabelecimento do "nós" e da importância do outro e do grupo como mediador no fortalecimento de vínculos familiares e comunitários. $\mathrm{O}$ grupo de mulheres foi, também, um espaço importante de acesso ao serviço, pois por meio dele puderam acessar seus direitos sociais.
\end{abstract}

Palavras-Chave: Política de Assistência Social; Grupos; CRAS; Diário de Campo.

\begin{abstract}
This study is the result of an intervention research fulfilled with a group of women participating in a regular activity in a CRAS of the metropolitan region of Florianópolis - SC. The objective of this paper is to present and discuss the field diary produced in between June 2017 to December 2018. The information was systematized with the help of the IRAMUTEQ software that allowed the identification of the study analysis categories through the Descending Hierarchical Classification (DHC), distinguishing four classes that were the subject of discussion and analyzed starting the J. P. Sartre groups dialectic. he results showed that the group experience allowed the establishment of the "we" and the importance of the other and the group as a mediator in fortification family and community ties. The women's
\end{abstract}


group was also an important space for access to the service, because through it they could access their social rights.

Key words: Social assistance policy; CRAS 2; Groups; Field diary.

\section{Resumen}

Este estudio es el resultado de una investigación de intervención realizada con un grupo de mujeres que participa de una actividad regular en un CRAS da la zona metropolitana de Florianópolis - SC. El objetivo de este artículo es presentar y discutir el diario de campo producido desde junio de 2017 hasta diciembre de 2018. Las informaciones fueran sistematizadas con la ayuda del software IRAMUTEQ que permitió la identificación de las categorías de análisis del estudio, a través de la Classificação Hierárquica Descendente (CHD), distinguiendo cuatro clases que fueran objeto de discusión analizadas desde la dialéctica de grupos de J. P. Sartre. Los resultados apuntaron que la experiencia grupal permitió el establecimiento del "nosotros" y la importancia del otro y del grupo como mediador en el fortalecimiento de los lazos familiares y comunitarios. El grupo de mujeres fue, también, un espacio importante para acceder al servicio, pues a través de él pudieron acceder a sus derechos sociales.

Palabras clave: Política de asistencia social; Grupos; CRAS; Diario de campo.

\section{Introdução}

Este artigo apresenta os resultados de uma pesquisa-intervenção realizada com um grupo de mulheres que frequenta um Centro de Referência de Assistência Social (CRAS) na região metropolitana de Florianópolis. Por meio do diário de campo, buscou-se trazer as considerações do caminho percorrido com este grupo, sobretudo, considerando o fato de que se traz as impressões de uma experiência de campo, na pesquisa e atuação profissional. A primeira autora deste trabalho atua como psicóloga no serviço, além de ter desenvolvido sua pesquisa de mestrado neste mesmo campo, a partir de uma intervenção já iniciada na sua experiência de trabalho. Neste trabalho, optamos ressaltar a experiência e dar destaque ao preconizado pela política de assistência social, mais especificamente, uma importante premissa que fundamenta a Proteção Social Básica, o fortalecimento de vínculos familiares e comunitários.

Um importante equipamento público para a execução da política de assistência social nos territórios, é o CRAS. Este serviço é a "porta de entrada" para os serviços da proteção social básica e destina-se a ser uma importante referência no atendimento às pessoas que vivem em situação de vulnerabilidade social, decorrente da ausência ou de precária renda, e da fragilização de vínculos 
afetivos, relacionais e de pertencimento social. Portanto, cabe ao PAIF (Serviço de Proteção e Atendimento Integral à Família) a execução do trabalho social com famílias, esta estratégia tem por finalidade fortalecer a função protetiva das famílias, prevenir a ruptura dos seus vínculos, promover seu acesso e usufruto de direitos e contribuir na melhoria de sua qualidade de vida (Brasil, 2009).

Dentre as possibilidades de execução da equipe PAIF para com a população do território, iremos dar destaque nesta escrita no que se refere as atividades que privilegiam a criação de grupos e coletivos no CRAS, uma vez que a aposta por este tipo de ação é sempre um grande desafio para as equipes e requer alguns apontamentos.

Para tanto, quando nos propomos a discutir sobre grupos, escolhemos seguir o referencial teórico-metodológico proposto por Jean Paul Sartre, o qual a ponta a necessidade de compreensão da época vivida, dos sujeitos envolvidos e do projeto em comum que os unifica. Assim, podemos melhor entender a história de uma formação grupal e os modos que ligam os sujeitos à sua permanência. Por certo, também optamos por selecionar duas obras do autor que são fundamentais para a compreensão do tema, Questão de Método (1987) e Crítica da Razão Dialética (2002). Em seu texto, Questão de Método, Sartre
(1987) introduz alguns elementos que serviram de base para a compreensão de sua obra posterior, Crítica da Razão Dialética. Nesta última, é possível reconhecer o esforço do autor em detalhar os fundamentos da gênese dos grupos e seus desdobramentos.

Entretanto, a fim de fundamentar importantes elementos, recorremos inicialmente ao conceito de dialética utilizado por Sartre que, muito embora esteja ancorado no conceito hegeliano, diferencia-se do conceito de totalidade. Sartre (1987) defende a dialética como algo que está perpetuamente em curso como história. Afirma o autor que o intelectual habituado ao método dialético considera os homens, suas objetivações, seus trabalhos e as relações humanas como o que há de mais concreto, pois recolocaos sem dificuldade em seu nível e encontra suas determinações gerais.

A dialética para Sartre não é uma lei, ou um conjunto delas. $\mathrm{Na}$ sua compreensão, "refere-se à totalidade como o movimento da história e como esforço teórico e prático para 'situar' um acontecimento, um grupo ou um homem" (Sartre, 1987, p. 159). Defende, portanto, a dialética como uma não totalidade, mas como um conjunto de estruturas de uma totalização em marcha. Propõe ainda, uma compreensão para uma dialética em que a inteligibilidade está ancorada na 
materialidade, em uma compreensão de que são os próprios sujeitos que fazem a dialética.

Anterior ao conceito de grupo propriamente, é necessário apresentar as considerações de Sartre no que se refere ao conceito de "série" (2002), uma vez que em nossa vida cotidiana, vivemos inúmeros momentos de experiências serializadas, qual seja, ficar em uma fila de lotérica, fila para assistir a um filme no cinema, para utilizar um transporte coletivo, como ônibus e metrôs. A essas experiências podemos designar uma espécie de conjunto humano sem unidade de envolvimento, troca ou qualquer implicação, são apenas sujeitos que buscam fazê-los de modo individual, alcançando objetivos próprios diante da perspectiva da escassez, ou de qualquer outro meio de obter aquilo que lhe é de desejo.

Esse contexto de serialização permite que, a partir desses próprios acontecimentos e ajuntamentos humanos, possa ocorrer o surgimento de grupos, pois são os próprios sujeitos quem, por meio da necessidade de resolução de suas necessidades, encontram, por intermédio dos outros, a unificação de subjetividades por meio da objetividade, a possibilidade do alcance dos seus fins transformando-a numa nova objetividade.
Enquanto na série existe apenas a dispersão dos sujeitos, a massa de pessoas na multidão, o grupo, por outro lado, resulta na totalização das reciprocidades. Importante destacar que a totalização não é sinônima de síntese, pelo contrário, para Sartre, uma totalização é sempre um recomeço, que não há fim, o movimento do grupo está sempre em curso. Lapassade (2016) acrescenta que, para Sartre, a vida dos grupos é feita de uma tensão permanente entre esses dois extremos, a serialização e a totalização. Sendo, portanto, este o motor da dialética do grupo, pois em diferentes momentos, há a luta constante contra a extinção e a possibilidade de retorno à serialidade.

O grupo em fusão marca a passagem da simples serialidade para um momento mais complexo no processo grupal. Por meio da práxis, os sujeitos buscam modificar o meio, as condições materiais a sua volta por meio da ação do grupo. O autor esclarece primeiramente que, nenhuma ação é dada a priori, ou seja, as determinações do grupo, seu motivo de ajuntamento, se darão a partir de uma necessidade à posteriori.

O grupo em fusão se constitui, portanto, da unificação dos sujeitos que, a partir de uma necessidade ou numa situação de perigo comum, buscam uma solução pelo fim do perigo, da escassez e ou necessidade. Com os olhos do comum, 
com as necessidades sentidas como comuns, seus membros buscam a resolução de suas necessidades, de maneira recíproca, por meio do outro, encontrando o que Sartre (2002) chama por mediação de cada um como terceiro. A este fato, em que podemos entender pela expressão "nós", que cada um do grupo e todos se tornam terceiros na relação, ou seja, a mediação entre todos faz surgir uma unificação capaz de ser a reciprocidade de cada um com todos e todos com cada um.

\section{Como acrescenta Lapassade} (2016), o grupo é a passagem dialética da quantidade para a qualidade, ou seja, não importam quantos são seus membros, quem será o último ou o primeiro, todos terão sua importância na unificação das necessidades sentidas como comum. Ou como concluiu Sartre, "Com efeito, pelo terceiro, a unidade prática, como negação de uma práxis organizada ameaçadora, revela-se através da constelação de reciprocidades" (Sartre, 2001, p. 467).

Sendo assim, a reciprocidade é mediada, uma vez que a ação de cada um é recíproca da ação de um outro, e o grupo se funda como a mediação dessas mediações. No entanto, o grupo vive em constante possibilidade de seu fim. $\mathrm{O}$ ato de extinguir-se é possível ao passo que seus membros não possuem mais interesses em comum e, quando isso acontece, a única possibilidade é o retorno à serialidade. Desta maneira, a fim de evitar a dispersão dos seus membros, o grupo busca modos de manter-se vivo e, para isto, utiliza a estratégia de afirmação de compromissos que sejam assumidos por seus membros, ou seja, livremente seus membros assumem o compromisso para manter o futuro do grupo, mediante um projeto em comum. Essa afirmação é fundamental para o estabelecimento de um grupo organizado.

Além da afirmação de compromissos, o grupo organizado, também se fundamenta com $o$ estabelecimento das divisões de tarefas e funções entre seus membros. "A palavra “organização" designa a ação interna pela qual um grupo define suas estruturas e, ao mesmo tempo, o próprio grupo como atividade estruturada que se exercita no campo prático sobre a matéria trabalhada ou sobre outros grupos" (Sartre, 2002, p. 539).

Ao definir, dirigir, controlar e corrigir sua práxis comum, a diferenciação é algo próprio da organização, com isto, cada grupo certamente se diferenciará de um outro. Assim, suas exigências responderão às necessidades próprias, e, portanto, esta é uma modalidade concreta da organização que se fez "diferenciável, ou se preferirmos, tornou-se tal que as diferenciações não quebram sua unidade e, ao mesmo tempo os problemas práticos 
podem revelar-se a ele através de problemas diferenciais." (Sartre, 2002, p. 541, grifo nosso).

O grupo ao trabalhar em razão de sua própria organização, passa a trabalhar sobre si, sua ação passa a ser voltada para a própria manutenção da sua condição como grupo organizado. Ao definir as funções de seus membros, tal ação buscará que as ações individuais agora integrem-se em ações em torno da práxis comum. Tal práxis estará sempre na dependência da própria organização e reorganização do grupo.

Quanto ao ato de organizar-se e reorganizar-se pressupõe uma ação a depender da criação do grupo. Assim, o ato de criação é a característica de um grupo que se pensa, se organiza e se trabalha constantemente. Tal necessidade apresenta-se como possibilidade de manter o grupo vivo, ativo no seu projeto, pois o seu oposto é um grupo sem um projeto comum, um grupo cristalizado em suas funções, podendo vir a ser um grupo hierarquizado, no qual não existe mais um "nós" permeando as relações.

\section{Método}

A partir das considerações acima, nossa intenção neste estudo é apresentar os resultados de uma pesquisa-intervenção realizada com um grupo de mulheres. Objetivamos com isto, compartilhar e refletir sobre a possibilidade de atuação com grupos e coletivos em CRAS que considerem sobretudo, a perspectiva das famílias, dos usuários e usuárias que o acessam. Em nossas posições, defendemos que este serviço público e estatal possa ser um lugar de garantia de direitos e que possa oportunizar as acolhidas, os encontros, o fortalecimento de vínculos e tantos outros possíveis quando se privilegia o agrupamento entre os humanos.

Para esta investigação foi realizada uma pesquisa-intervenção em um CRAS da região metropolitana de Florianópolis durante o período de junho de 2017 a dezembro de 2018, junto a um grupo de convivência de mulheres já existente no serviço. Este grupo é fruto de uma experiência que iniciou por meio de oficinas de criação artísticas no ano de 2016, realizada por uma das autoras em sua função técnica no próprio CRAS. Muito embora, mesmo sem oficineiros e insumos para as atividades de artesanato, as usuárias decidiram por continuar a atividade no ano de 2017. Neste mesmo ano, fomos constando que havia um grupo se formando ali, sobretudo, manifestado pelo desejo das próprias usuárias. Logo, já no mestrado, a pesquisa-intervenção, foi uma aposta em conhecer melhor o funcionamento e manutenção deste grupo ao longo dos encontros. Deste modo, 
foram realizados 44 encontros durante o período da pesquisa.

Uma das ferramentas de registro da pesquisa foi a produção de um diário de campo. Ao utilizar o diário de campo como material de análise, nossa intenção é apresentar a experiência, proporcionando dar destaque ao vivido e ao compartilhado entre pesquisadores e sujeitos envolvidos.

As informações produzidas no diário de campo foram analisadas por meio do software informático IRAMUTEQ (Interface de $R$ pour les Analyses Multidimensionnelles de Textes et de Questionnaires). De acordo Silva e Enumo (2017), a utilização deste software possibilita tanto análises quantitativas, apresentando a frequência das palavras, quanto qualitativas. Esta possibilidade colocada pelo sistema permitiu que por meio da Classificação Hierárquica Descendente (CHD) pudéssemos extrair deste material as categorias de análise para o estudo. A CHD, nas palavras de Camargo e Justo (2014), consiste em classificar os segmentos de texto em função dos seus respectivos vocabulários e, por conseguinte, dividindo-os com base na frequência e qui-quadrado.

Quanto as mulheres que participaram desta pesquisa, estas pertencem a dois bairros que compõe o território do CRAS e possuem idades entre 32 anos e 77 anos. Por ser uma atividade coletiva, realizada pelo serviço desde 2016, muitas usuárias passaram pela atividade. No entanto, vale registrar que 14 delas permaneceram até o encerramento da pesquisa.

\section{Resultados e discussão}

O corpus diário de campo, submetido ao software IRAMUTEQ, foi dividido pelo método de CHD em quatro classes distintas, sendo possível inclusive verificar a relação entre as classes. Considerando que foram realizados 44 encontros do grupo durante o tempo estabelecido para a pesquisa, tais registros foram submetidos à análise em que esses textos foram classificados em 294 segmentos de texto, retendo-se um total de $78,91 \%$ deste material pelo sistema.

No texto a ocorrência de palavras totais foram de 10.610, sendo 2.214 palavras distintas. $\mathrm{O}$ corpus se dividiu em 4 classes de segmentos de texto a partir da CHD realizada e, as palavras apresentadas no dendrograma (Figura 1) tiveram frequência maior e igual a 5. Apresentadas as ramificações e classes, fizemos a escolha por nomeá-las e apresentá-las na seguinte disposição: Classe 2 - O serviço $(24,14 \%)$, Classe 4 - Tecer $(24,14 \%)$, Classe 3 - Afetos $(21,98 \%)$ e Classe 1 Encontros (29,74\%). É importante destacar que, a importância da palavra para a classe foi evidenciada pelo seu Qui-Quadrado $\left(\chi^{2}\right)$ 
de associação com classe, conforme é

possíve

verificar

na Figura

1.

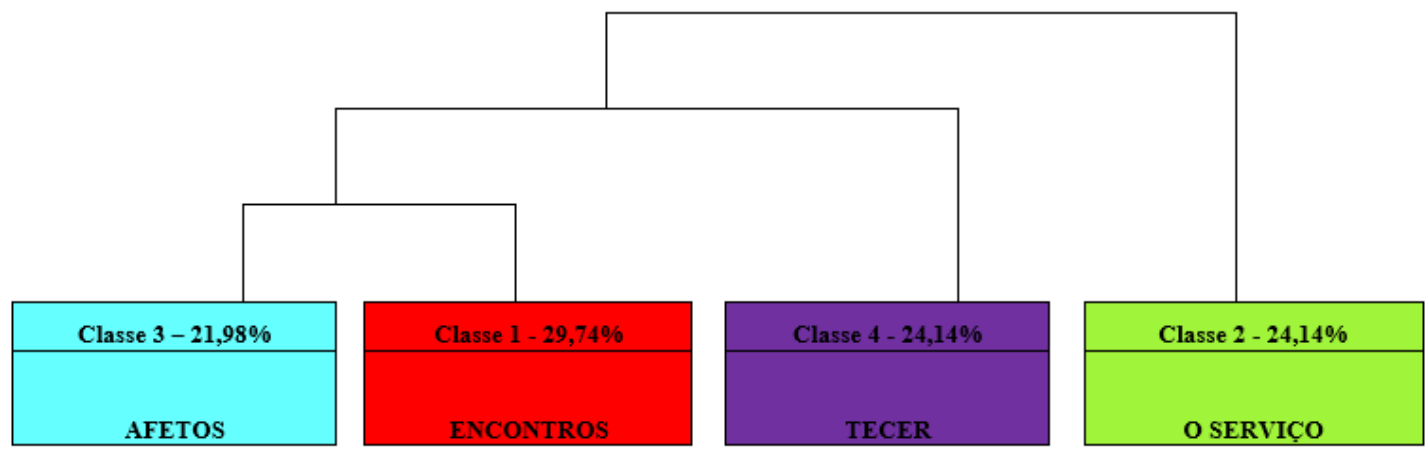

\begin{tabular}{|c|c|c|}
\hline Palavra & Freq. & $\mathbf{X}^{\mathbf{2}}$ \\
\hline amigo & 9 & 33.23 \\
\hline coletivo & 7 & 25.62 \\
\hline secreto & 6 & 21.86 \\
\hline presente & 8 & 20.51 \\
\hline casa & 11 & 19.52 \\
\hline agradecer & 5 & 18.14 \\
\hline final & 8 & 17.34 \\
\hline também & 15 & 15.77 \\
\hline gostar & 8 & 14.73 \\
\hline rifa & 7 & 14.05 \\
\hline $\begin{array}{c}\text { levar } \\
\text { preparar }\end{array}$ & 6 & 13.58 \\
\hline $\begin{array}{c}\text { falar } \\
\text { inclusive }\end{array}$ & 22 & 13.52 \\
\hline
\end{tabular}

\begin{tabular}{|c|c|c|}
\hline Palavra & Freq. & $\mathbf{X}^{2}$ \\
\hline entender & 6 & 14.55 \\
\hline encontro & 23 & 14.24 \\
\hline grupo & 37 & 12.20 \\
\hline rede & 5 & 8.47 \\
\hline perceber & 5 & 8.47 \\
\hline demais & 5 & 8.47 \\
\hline conseguir & 5 & 8.47 \\
\hline tema & 12 & 8.30 \\
\hline reunião & 6 & 8.12 \\
\hline discutir & 6 & 8.12 \\
\hline roda & 21 & 7.65 \\
\hline próprio & 6 & 6.11 \\
\hline experiência & 6 & 6.11 \\
\hline combinar & 6 & 6.11 \\
\hline
\end{tabular}

Figura 1. Dendrograma da Classificação

Hierárquica Descendente relativa ao

corpus Diário de Campo. Dados obtidos

A primeira classe a diferenciar-se do restante do corpus foi a classe 2, denominada o serviço. Esta foi responsável por $24,14 \%$ do conteúdo analisado. Está representada na figura pela cor verde. A palavra de maior destaque na classe é serviço, seguidas de outras como, trazer, atender, acesso, saúde, social e

\begin{tabular}{|c|c|c|}
\hline Palavra & Freq. & $\mathbf{X}^{2}$ \\
\hline Material & 16 & 37.30 \\
\hline Pano & 9 & 29.43 \\
\hline Anterior & 9 & 29.43 \\
\hline Toalha & 9 & 24.76 \\
\hline Produzir & 10 & 24.22 \\
\hline Atividade & 27 & 22.27 \\
\hline Artesanato & 12 & 21.61 \\
\hline Prato & 8 & 21.44 \\
\hline Crochê & 8 & 21.44 \\
\hline Trabalho & 9 & 20.98 \\
\hline Pintura & 6 & 19.36 \\
\hline comprar & 7 & 18.17 \\
\hline retorno & 5 & 16.06 \\
\hline dinheiro & 8 & 14.89 \\
\hline desejar & 7 & 12.00 \\
\hline compra & 5 & 11.79 \\
\hline
\end{tabular}

\begin{tabular}{|c|c|c|}
\hline Palavra & Freq. & $\mathbf{X}^{2}$ \\
\hline serviço & 12 & 34.95 \\
\hline trazer & 22 & 29.99 \\
\hline atender & 8 & 26.04 \\
\hline acesso & 7 & 22.68 \\
\hline saúde & 6 & 19.36 \\
\hline social & 8 & 17.81 \\
\hline participação & 11 & 16.49 \\
\hline violência & 5 & 16.06 \\
\hline municipio & 5 & 16.06 \\
\hline profissional & 10 & 15.84 \\
\hline atendimento & 7 & 14.71 \\
\hline $\begin{array}{c}\text { tudo } \\
\text { questionar }\end{array}$ & 7 & 12.00 \\
\hline dificuldade & 6 & 11.71 \\
\hline $\begin{array}{c}\text { comunidade } \\
\text { com }\end{array}$ & 8 & 10.52 \\
\hline
\end{tabular}

com as entrevistas por meio do

software IRAMUTEQ

participação. O conteúdo desta classe remete ao processo de trabalho e de gestão que envolve o CRAS enquanto serviço público previsto pela política pública de assistência social.

Diante desses achados, nos ocorre problematizar sobre a precarização das políticas públicas e os cortes no financiamento público, no atual momento 
do Brasil. A extinção de alguns ministérios, políticas e serviços apontam para um panorama de desmonte de um estado que nos últimos 15 anos buscou algumas garantias para a população em maior situação de vulnerabilidade social. De fato, a precarização sempre esteve presente, uma vez que esta é uma estratégia utilizada pelo projeto neoliberal. Yamamoto e Oliveira (2010) esclarecem que tal questão parte de uma agenda em que estão previstas a elevação de taxas de juros, a diminuição da taxação de altos rendimentos, o desemprego, a repressão ao movimento sindical, corte de gastos sociais pela desmontagem dos serviços, as privatizações, enfim, promovendo o estabelecimento de um "Estado mínimo".

As considerações colocadas pelos autores, ganham muita força no governo atual, e se a política de assistência social caminhava a duras penas, a curto e médio prazo não sabemos sobre o seu futuro. De fato, perdemos o status de ministério para sermos apenas uma secretaria no governo atual ${ }^{1}$.

A esta situação colocada, há o impacto significativo no processo de trabalho das equipes nos CRAS, ora pela ausência de trabalhadores que sejam suficientes para execução dos atendimentos à população, ora pela ausência de políticas que garantam o acesso aos benefícios aos usuários, e de modo amplo, o não efetivo investimento na política de assistência social. Neste momento, não falamos de melhorias, nos limitamos enquanto trabalhadores/as a defender a manutenção de algumas garantias que foram conquistadas, inclusive buscando a preservação de aspectos técnicos e éticos, em detrimento da caridade da filantropia e do primeiro damismo, que ganham força no cenário atual.

Nesta direção, nos ocorre pensar que é fundamental que os trabalhadores/as estejam atentos e críticos ao não se deixarem enganar por alguns artifícios. Dizemos isto, pois na ânsia de promover o acesso aos direitos, há mecanismos cada vez mais contundentes pelo monitoramento e fiscalização das populações. Couto (2015) considera fundamental escapar de algumas armadilhas colocadas nesse campo, já que há a perspectiva do adestramento da população usuária, a expectativa de construir modelos ideais de famílias, de serviços e territórios, que, de certa maneira, perdem as possibilidades de se problematizar as condições de vida, de lutas e de resistência das populações. Acrescenta ainda a necessidade de garantir um serviço de qualidade que atenda às necessidades sociais da população.

Novamente, recorremos à problemática de para quem devemos fazer 
a política social. Para essas questões, retomamos a discussão sobre a concepção de sujeitos que devemos nos apoiar. Assim, reforçamos que durante o processo de pesquisa, com o grupo de mulheres no CRAS, o pressuposto sempre foi a compreensão de sujeitos de direitos e não mais o entendimento que marcou a história da assistência social brasileira, deste como sendo o carente, o necessitado e o assistido. Os cadernos de orientações técnicas, e outros instrumentos da política ${ }^{2}$, foram utilizados neste estudo, bem como são utilizados pela equipe do CRAS para referendar as suas ações, pois é fundamental que não nos percamos nas armadilhas.

A classe 4, que na cor lilás, se destacou no corpus a partir da segunda partição, a qual denominamos Tecer, representou $24,14 \%$ dos segmentos de textos classificados. A palavra de maior destaque na classe é material, seguida de outras como: pano, anterior, toalha, produzir, atividade, artesanato entre outras. O conteúdo desta classe representa a utilização do artesanato como mediador dos encontros, pois para além do seu caráter de mobilizar e motivar as usuárias a participarem de atividades coletivas, possibilitou a criação, o compartilhamento e a troca de saberes nos encontros.

De fato, o recurso do artesanato inicialmente permitiu que as mulheres se interessassem em participar de uma atividade coletiva. A equipe também se propôs a uma outra forma de relação com as usuárias, que em função de não saber ao certo o caminho a percorrer, se propôs a decidir e a construir junto com elas. $\mathrm{Na}$ experiência do grupo de convivência de mulheres estudado, nos propomos a estabelecer uma nova relação com as usuárias, ou seja, não ser apenas responsável pela condução do grupo, mas também estar presente na confecção do artesanato. Desta maneira, é possível observar tal perspectiva durante o processo da pesquisa:

Neste dia fiquei apenas fazendo artesanato $e$ acompanhando as mulheres nas conversas. Sempre sou solicitada por elas a participar fazendo algo, a estar junto com elas. Durante esses anos aprendi a fazer fuxico, a pintar pano de prato e a me aventurar com o ponto cruz. Como este ano elas optaram pelo patchcolagem, neste dia foi possivel aprender o ponto caseado e foi com grande satisfação que trocamos ideias e passamos a tarde assim, algumas no bordado, outras no crochê e, também, no patchcolagem. Durante este ano também amadurecemos essa ideia, nem todas precisam fazer as mesmas coisas. As participantes vão se articulando entre si e de acordo com as habilidades de cada uma. Assim, não temos mais uma única atividade como no ano anterior. Penso que melhorou a participação e a frequência dos encontros, pois ouvi de 
uma delas que não havia participado no ano anterior, pois não gostava de pintura em pano de prato. (D.C 12/07/2018).

Com a utilização do artesanato, foi possível, inclusive, que o grupo continuasse a existir e suas atividades se mantivessem até os dias de hoje. Inicialmente, buscávamos a aproximação dessas mulheres com o CRAS para trabalharmos temas pertinentes a este grupo populacional. No entanto, em outubro de 2017, uma das participantes sugere a venda das toalhas que o grupo produziu até aquele momento:

\begin{abstract}
Deste modo, uma delas sugeriu que pudéssemos vender algumas toalhas para conseguir dinheiro para comprarmos materiais para o grupo, visto que neste evento tem a feira de artesãos. As participantes gostaram da ideia $e$ falaremos mais sobre quando estivermos próximo da data (D.C 05/10/2017).
\end{abstract}

Esta importante decisão do grupo permitiu inclusive que a pesquisaintervenção pudesse se entender até 2018, ao passo que não determinamos inicialmente um tempo para a pesquisa, que seguiu o movimento do próprio grupo. No referido ano, foi possível atender melhor o desejo das participantes, pois tínhamos dinheiro para a compra dos materiais necessários, pois o que a prefeitura enviava era insuficiente para o número de participantes e para as variedades de artesanatos que elas queriam produzir.

É importante deixar registrado; que ao longo de sua existência, o grupo contou com apenas seis meses de oficinas orientadas por profissionais da área, enviadas pela prefeitura. Durante o restante do tempo foram as próprias participantes, com os mais diversos conhecimentos e habilidades em artesanato, que foram as facilitadoras dos encontros. A troca de saberes sempre esteve presente na racionalidade do grupo.

No que se refere a classe 1, denominada Encontros, a maior do corpus, representou 29,74\% dos segmentos de texto classificados. Encontra-se representada na cor vermelha nas figuras 3 e 4. A palavra de maior frequência na classe é entender, seguida de encontro, grupo, rede, perceber. O conteúdo desta classe trata principalmente das questões relativas à experiência dos encontros, do grupo e das rodas de conversa.

Quanto a classe 3, representada pela cor azul claro, foi denominada de Afeto, e representou $21,98 \%$ dos segmentos de texto classificados, a palavra de maior frequência na classe é amigo, seguida de coletivo, secreto, presente, casa e agradecer e demais palavras que se encontram representadas na figura 1. O 
conteúdo desta classe retrata a amizade e o caráter positivo destes espaços de encontro no CRAS. Desta maneira, decidimos por apresentá-las juntas, pois a semelhanças convergem para os temas, os quais queremos iluminar com a teoria de grupos proposta por Sartre e seus interlocutores.

Com isto, vale ressaltar que, ao buscar compreender como o grupo de mulheres se constituiu, apesar de tantas dificuldades, temos certo que a escassez, já colocada lá no início dos anos de 2017, foi decisiva para que as participantes, que naquele momento eram apenas uma série, fossem encontrando uma alternativa para a sobrevivência daquele espaço promovido pelo CRAS. Maheirie (2010) defende que quando ocorre a fusão da série, não há como possibilidade de pensar, sentir e agir de forma individualizada e isolada. Nestes momentos, os sujeitos passam a entrelaçarse com outros sujeitos em torno de um projeto em comum. Processos estes, que são sempre abertos e inacabados.

A equipe do CRAS sempre buscou dar apoio às decisões daquelas mulheres e respeitar o movimento que estava sendo formado por aquele coletivo, pois o desejo da equipe em ter um grupo, no qual se pudesse alcançar algumas prerrogativas previstas pela política, fez criar um movimento de resistência, de criação e de promoção de espaços de negociação com essas mulheres. As mulheres e a equipe foram encontrando, em certa medida, caminhos possíveis para continuar.

O grupo pesquisado nasceu ao resistir e superar uma determinada situação, "a unidade de suas sínteses, portanto, nos elucida o projeto de ser do grupo - a sua biografia." (Freitas, 2018, p. 541). Assim, aquelas mulheres juntas permitiram trocar experiências e ensinar umas às outras, quando não havia oficineiros. Organizaram a venda dos seus produtos para arrecadar dinheiro para comprar materiais, quando não havia possibilidades ofertadas pela prefeitura. Nestes momentos, observamos que as usuárias tinham objetivos em comum e se lançaram para o alcance e a continuidade deles. Observamos, neste momento, o nascimento do grupo.

Ao longo de sua trajetória, o grupo criava espaços e negociava estratégias para sua existência e continuidade. Um registro realizado pela psicóloga e pesquisadora, em diário de campo, nos traz essa ideia:

Conforme já mencionado em diversos momentos pelas usuárias, trouxe a questão da frequência dos encontros do grupo. Assim, como é de desejo da maioria, o grupo ocorrerá semanalmente às quintasfeiras. Um outro aspecto que aprimoramos com o tempo foi a realização de um planejamento de ações e intenções que, aliás, foi uma ideia colocada por uma das 
participantes. Neste dia realizamos o encontro do grupo com o objetivo de planejarmos o ano de 2018. Com isto, fizemos a roda de conversa e fomos elencando os objetivos e o que iríamos fazer durante o ano, bem como fazermos alguns acordos necessários para a continuidade do grupo. (D.C 21/09/2017 15/03/2018).

Tais registros remetem à importância da equipe PAIF abrir-se para a possibilidade de construir espaços coletivos e grupais com os usuários do serviço. Com isto, é possível que sejamos mais assertivos em atendermos as necessidades dos sujeitos que nos procuram. Souza (2018) aponta que a Psicologia, enquanto categoria prevista no Sistema Único de Assistência Social (SUAS), encontra nas práticas grupais um terreno conhecido em sua formação. No entanto, faz importantes reflexões como: os temas a serem discutidos, os horários ofertados, o desconforto para alguns usuários em participar apenas de práticas coletivas, as relações de poder e inclusive, “[...] sobre a disposição das(os) coordenadoras(es) de grupo de realmente compartilhar o protagonismo com $\mathrm{a}(\mathrm{o})$ usuária(o) na proposição de suas práticas, entre outros aspectos." (Souza, 2018, p. 229). Assinala ainda, para a importância de valorização de iniciativas que já acontecem na comunidade que poderiam ser incorporadas ao CRAS.

Ao discutir relativamente sobre as questões grupais e coletivas no CRAS compreendemos que há um duplo desafio lançado, qual seja, a proposição de iniciativas, ou a incorporação das que já existem na comunidade e a manutenção desses espaços. Assim, como estamos apresentando e problematizando neste texto, não basta apenas o desejo, o engajamento da equipe, há que se considerar o que também deseja os usuários que participam desses espaços. Sobre a continuidade, não podemos fazer afirmações, pois somente os sujeitos envolvidos nos grupos, por meio da práxis grupal é que definirão os caminhos a seguir.

O grupo por ser apenas ato e, sua razão de existir residir na pura ação dos sujeitos, é que vamos encontrar o grupo trabalhando constantemente a si. $\mathrm{O}$ fazer de um grupo é a sua ação e um permanentemente fazer. "Ele se trabalha para se dar, em uma espécie de criação contínua, essa unidade ontológica que não tem, que jamais terá e da qual conserva, contudo, o desejo [...]" (Lapassade, 2016, 267).

Todavia, um outro importante aspecto a ser destacado, que vem a considerar a perspectiva do "nós" grupal, é o constante exercício para que de fato isto 
aconteça, e podemos assegurar que este se constituiu num grande desafio. $\mathrm{Na}$ contemporaneidade, há a valorização iniciativas individuais em detrimento das coletivas. O momento atual nada tem favorecido as trocas e compartilhamentos, e isto foi registrado durante a pesquisa:

Sobre a noção do coletivo, venho trabalhando muito com este grupo. Percebo que por vezes temos iniciativas pessoais ou, lançarem sobre mim uma responsabilidade ou iniciativa. Sempre trago todas as discussões para o consenso do grupo, em nenhum momento o dinheiro é gasto sem a anuência e a participação delas. O exercício do nós é trabalhado a cada encontro, seja nas combinações diárias ou em acordos futuros. Sempre levo temas e pautas que elas desejam e com isto, venho trabalhando a possiblidade de fala, de se permitirem escolher e tomar decisões coletivas. $O$ que espero com essas ações, é que esse exercício realizado neste grupo seja útil na vida diária de cada mulher, que elas possam encontrar meios de fazerem escolhas e decidirem por suas vidas. (D.C 23/08/2018).

Sobre os efeitos que um grupo pode gerar, Rubini (1999) enfatiza o surgimento de um novo tipo de relação, no qual cada sujeito torna-se para si e para os outros uma pessoa com a qual é necessário contar, havendo uma transformação qualitativa das relações, ou seja, "cada um é o grupo e o grupo é cada um" (Mahieirie, 2010, p. 267). Assim, ao apostar em experiências de grupos nos serviços da assistência social, pressupõe o desenvolvimento de ações que também vão ao encontro da concepção de fortalecimento de vínculos familiares e comunitários previstos pela política.

O fortalecimento de vínculos familiares e comunitários é um dos pilares centrais do trabalho do PAIF, assim como a matricialidade familiar e o território. Os cadernos de orientações técnicas versam ainda para a valorização do caráter subjetivo. Todavia, destaca que ao assumir a subjetividade como um dos elementos do trabalho social com famílias, não é negar ou diminuir a importância de outras questões objetivas como a vulnerabilidade e a desigualdade social que atingem as famílias. Tais definições propostas, vem a corroborar inclusive com a perspectiva teórica e metodológica orientada na pesquisa, qual seja, “Ao contrário, é reconhecer que os serem humanos são historicamente constituídos pelo entrelaçamento das dimensões subjetivas e objetivas, sendo, portanto, plenos de capacidade de mudança." (Brasil, 2012ª , p. 19).

Os registros também fazem referência a esses momentos de encontros que produzem efeitos no grupo e, seguramente, para essas mulheres que dele participam: 
Hoje foi um dia especial. Recebemos a oficineira, tão esperada pelo grupo. Também neste dia iríamos comemorar nossos 2 anos da existência. Antecipadamente solicitamos que quem pudesse trazer algo para o café, seria muito bem-vindo, pois, com isto, faríamos um lanche coletivo em comemoração. A medida em que foram chegando, verifiquei a mesa sendo acrescida de bolos, pães, bolachas e sucos, coisas preparadas por elas, inclusive. (D.C 20/09/2018).

As festas,-são uma rotina no grupo e nelas são comemorados os aniversários, o encerramento do ano e de tudo mais que elas queiram comemorar. A fala de uma participante resgatada no diário, ilumina esta compreensão. "Não é o que eu faço ali no grupo, é eu estar com vocês, de tá rindo, é estar com vocês." (D.C 13/12/18).

Ao longo do tempo, ao mediar este grupo, foi possível perceber que muitas mulheres se tornaram amigas, havia trocas de mensagens em celular, o grupo de Whatsapp delas, a visita que uma fazia à casa da outra, eventos e passeios que foram juntas na comunidade, e isto ia sendo compartilhado por elas durante os encontros. $\mathrm{O}$ fortalecimento dessas relações produziu efeitos subjetivos importantes. Reforçamos isto também em virtude das características do território, pois a população é originária de diversas regiões do estado de Santa Catarina e de outros estados do país; e a ausência de rede de apoio familiar e comunitário é algo comum. Um outro aspecto a mencionar é a falta de renda suficiente para visitar parentes em outras cidades e até mesmo dentro dela, o que possibilita gerar isolamento social. Para algumas mulheres, o grupo tornou-se uma rede social importante. Isto justifica, portanto, a realização de atividades grupais no âmbito do CRAS, uma vez que estas famílias e indivíduos são vistos como prioritárias nos atendimentos e o grupo pode ser um grande mediador desses encontros.

Para além de buscar uma aproximação entre elas, fomos um pouco adiante durante a pesquisa; também estávamos atentas em promover a aproximação delas com a comunidade. Assim, promovemos e organizamos a participação do grupo em um importante evento no bairro. A maioria das mulheres estava resistente em expor seus produtos, tendo em vista que consideravam que eles não eram suficientes ou que não tinham qualidade. No entanto, ponderou-se que o objetivo da participação no evento era de tomar conhecimento e experimentar participar de uma feira de artesanato. Fezse considerações sobre a quantidade de coisas boas e bonitas para serem expostas, pois também nada garantiria a venda dos produtos, mas sim, estaríamos participando de um evento comunitário, sendo esta 
nossa primeira participação enquanto um coletivo a expor produtos. De fato, as vendas não foram muito efetivas, mas naquele espaço puderam conversar com outros expositores e experimentar essa atividade. Algumas já haviam expostos os seus trabalhos em outros locais, mas para muitas era algo novo. Essa iniciativa tinha o caráter de dar visibilidade ao trabalho do grupo, mas que também elas próprias pudessem vislumbrar uma possibilidade de ganho de renda com a venda, uma vez que sempre levávamos a produção do grupo e a que elas produziam individualmente.

Um outro aspecto importante a mencionar foi a implantação das rodas de conversa durante o período da pesquisa. Quando os primeiros encontros foram iniciados em 2016 não havia um espaço destinado para isto, ou seja, as mulheres chegavam ao grupo e dirigiam-se diretamente para as atividades de artesanato. Entretanto, sempre esteve como projeto a ser executado com este grupo, a possibilidade de discussão de temas de interesses para a assistência social, pois queríamos sair do lugar comum, um grupo de mulheres que fazem artesanato, já que estas são práticas rotineiras e já existentes em diversas comunidades. Entendíamos que, por ser um grupo dentro de uma política pública, era nosso dever trabalhar alguns temas ainda latentes na sociedade.
Como algumas experiências de conversas já haviam sido experimentadas e surtiram efeitos importantes, percebeu-se a possibilidade de inclusão da roda de conversa como ferramenta para o desenvolvimento da pesquisa e para o próprio grupo. "A roda de conversa é no âmbito da pesquisa narrativa, uma forma de produzir dados em que o pesquisador se insere como sujeito da pesquisa pela participação na conversa e, ao mesmo tempo, produz dados para discussão." (Moura; Lima, 2014, p.99). Assim, foi negociada a primeira hora dos encontros para a roda de conversa. Nestes momentos, foi possível exercitar a possibilidade de fala e de escuta. Trouxemos temas e convidados para estes momentos. Temas que, aliás, foram sendo escolhidos por elas também. Ao longo do tempo foi extremamente positivo ver algumas mulheres se soltando e encontrando um espaço de fala e de partilha. Nesse processo, a socialização de trocas de experiências permitiu que caminhássemos para a construção de novos fazeres e conhecimentos.

A roda de conversa também foi um importante instrumento para a negociações entre o grupo, pois neste espaço, discutíamos sobre qual artesanato fazer, sobre o que e como arrecadar dinheiro, bem como o que comprar, ou seja, nada no grupo era decidido fora deste espaço, tudo 
era colocado enquanto ideia para apreciação e discussão de todas. Até hoje é possível constatar que as participantes vão chegando aos encontros e se posicionam na roda e, assim, já começam as conversas.

Por fim, considera-se que o grupo de convivência de mulheres tornou-se um grupo organizado e autorreflexivo. A práxis comum é a constante luta e resistência pela manutenção deste espaço dentro do CRAS. Ao organizar, planejar e dividir as tarefas, este grupo trabalha para manter-se vivo, produzindo encontros, afetos e subjetividades, continuando ativo e engajado no seu projeto.

\section{Considerações Finais}

Este grupo que se formou anteriormente à pesquisa e mantem-se após ela é de fato uma experiência exitosa no campo da política de assistência social. A experiência grupal certamente foi fortalecida durante esse período com os instrumentais teóricos-metodológicos utilizados e algumas dessas ferramentas e compreensões são mantidas até hoje.

Todavia, devemos atribuir ao sucesso da atividade a implicação da equipe PAIF e do interesse das mulheres pela atividade, ainda que seja frequente a falta de materiais, lanche e oficineiros para a sua execução. Tal situação se deve às poucas oportunidades oferecidas pela Secretaria de Assistência Social do município. Assim, nesses três anos de existência, as mulheres vêm buscando, como grupo, encontrar alternativas para a venda dos seus produtos e com isto mantêlo.

$\mathrm{Na}$ análise realizada foi possível compreender a importância do recurso do artesanato como mediador para a inserção dessas mulheres no grupo. Tal iniciativa, que foi observada em 2014 pela equipe PAIF, permitiu que o CRAS pudesse oferecer para as mulheres do território algo que, aos olhos da equipe, era do interesse da maioria. Assim, ao ofertar uma atividade, é importante que a equipe PAIF esteja atenta ao que mobiliza e motiva os usuários a participarem de propostas coletivas no CRAS, ou, até mesmo, propor atividades que já estejam de algum modo acontecendo na comunidade. Com isto, talvez sejamos mais assertivos na aproximação da equipe PAIF e usuários do serviço.

A perspectiva da dialética dos grupos, permitiu a compreensão sobre o grupo pesquisado e, também, a aproximação entre a matriz teórica com os cadernos de orientações técnicas e normativas ministeriais. Encontramos, deste modo, uma matriz teórica conceitual semelhante, pois tanto a teoria utilizada quanto os documentos oficiais apontam para respeito aos usuários, usuárias e famílias como sujeitos de direitos e, 
sobretudo, oportunizando e valorizando a liberdade no pensar, no agir, na capacidade e possibilidade de escolha individual e/ou coletiva.

Por fim, o grupo de convivência de mulheres é um espaço importante de acesso às usuárias do serviço, pois muitas delas entraram no grupo e depois disso, foram conhecendo e acessando os direitos. O espaço grupal também permitiu ser o próprio grupo uma rede de apoio importante. Ao longo da pesquisa foi possível promover o acesso a direitos, ao debate, à valorização do protagonismo e, sobretudo, foram fortalecidos os vínculos, prerrogativa importante na execução do trabalho do PAIF.

Um ponto importante a destacar neste artigo é a possibilidade de dar visibilidade a uma experiência coletiva, por meio da práxis grupal, em seu movimento incessante, aberto e inacabado, de articulação de singularidades em torno de um horizonte de possibilidades coletivas. Com isso, apontamos a necessidade e a potência de fortalecer os laços entre universidade, serviço e usuárias da assistência social na promoção da cidadania, por exercícios de emancipação em territórios específicos. Com isso, queremos somar esforços e entrelaçar estratégias de trabalho e de investigações em torno da ideia do comum e das práticas de equipes que compõem as políticas de assistência social no Brasil.

\section{Notas}

${ }^{1}$ Informações referentes podem ser acessadas em: http://mds.gov.br/acesso-ainformacao/institucional

2 Brasil. Política nacional de assistência social. Ministério do Desenvolvimento Social e Combate à Fome. Secretaria Nacional de Assistência Social. Brasília.

BRASIL. Orientações Técnicas: $O$ Serviço de Proteção e o Atendimento Integral à família - PAIF, segundo a Tipificação Nacional de Serviços Socioassistenciais. Ministério do Desenvolvimento Social e Combate à Fome. Secretaria Nacional de Assistência Social., Vol. 1 e 2 - $1^{a}$ Edição. Brasília, 2012.

\section{Referências}

Brasil. (2012). Orientações Técnicas sobre o PAIF - volume 2. Ministério do Desenvolvimento Social e Combate à Fome. Secretaria Nacional de Assistência Social. Brasília, MDS.

Brasil. (2009). Tipificação nacional dos serviços socioassistenciais. 
Ministério do Desenvolvimento Social e Combate à Fome. Secretaria Nacional de Assistência Social. Brasília, MDS.

Camargo, B. V, \& Justo, A. M. (2014). Estudos qualitativos e o uso de software para análises lexicais. Caderno de artigos: X SIAT \& II SERPRO. Duque de Caxias, RJ.

Couto, B. R. (2015). Assistência social: direito social ou benesse? Serviço Social \& Sociedade, (124), 665677. https://doi.org/10.1590/01016628.045

Freitas, S. M. P. (2018). Sartre, Psicologia de Grupo e Mediação Grupal. (Tese de doutorado). Programa de Pós-Graduação em Psicologia - Universidade Estadual de Maringá: Paraná.

Lapassade, G. (2016). Grupos, organizações e instituições. $5^{\circ} \mathrm{ed}$. Rio de Janeiro: Vozes.
Maheirie, K. (2010). O músico, os processos de exclusão e relações grupais no trabalho acústico. Em: K. B. (Org.). O trabalho de quem faz arte e diverte os outros, 265270. Goiás: PUC.

Moura, A. F, \& Lima, M. G. (2014). A reinvenção da roda: roda de conversa: um instrumento metodológico possível. Revista Temas em Educação, 23 (1), 98106.

Rubini, C. (1999). Dialética dos grupos: contribuições de Sartre à compreensão dos grupos. Revista Brasileira de Psicodrama, 7(2). Recuperado de http://www.saude.campinas.sp.gov. br/saude/programas/integrativa/curs o_PICS/encontro_2016_08_04/Dial etica_dos_Grupos_contribuicoes_d e Sartre.pdf

Sartre, J. P. (2002). Crítica da razão dialética. Rio de Janeiro: DP\&A. 
Sartre, J. P. (1987). Questão de método.

Coleção “Os pensadores”. São Paulo: Ed.

Abril.

Silva, A. M. B \& Enumo, S. R. F. (2017). Descrição e análise de uma intervenção psicológica com bailarinos pelo Software IRAMUTEQ. Temas em Psicologia, 25(2), 577-593. https://dx.doi.org/10.9788/TP2017. $\underline{2-11 P t}$

Souza, L. V. (2018). Contribuições construcionistas sociais para o trabalho com grupos na proteção social básica. E: M. P. Cordeiro; B. Svartman \& L. V, Souza (Orgs) Psicologia na Assistência Social: um campo de saberes e práticas (p.226-238) $1^{\text {a }}$ edição. São Paulo, Instituto de Psicologia.

Yamamoto, O. H. \& Oliveira, I. F. (2010). Política Social e Psicologia: Uma Trajetória de 25 anos. Psicologia: Teoria e Pesquisa. Psicologia: Teoria e Pesquisa, 26(spe), 9-
24. https://dx.doi.org/10.1590/S010 $\underline{2-37722010000500002}$

Deise Lucia Antunes Lopes é psicóloga formada pela Universidade do Sul de Santa Catarina (UNISUL) e mestranda no Programa de Pós-Graduação em Psicologia (PPGP) na Universidade Federal de Santa Catarina (UFSC) na área de Psicologia Social e Cultura.

E-mail: deantuneslopes@gmail.com ORCID:https://orcid.org/0000-0003-0353$\underline{2697}$

Kátia Maheirie é professora doutora titular na Universidade Federal de Santa Catarina (UFSC), no Departamento e no Programa de Pós-graduação em Psicologia (PPGP).

E-mail: maheirie@gmail.com

ORCID:https://orcid.org/0000-0001-5226-

$\underline{0734}$

Ana Maria Justo é professora doutora adjunta do Departamento de Psicologia na Universidade Federal de Santa Catarina (UFSC).

E-mail: justoanamaria@gmail.com

ORCID:https://orcid.org/0000-0003-2056$\underline{3575}$

Enviado em: 28/11/19- Aceito em: 22/09/20 